\title{
Effects of the Variety and Content of Natural Pozzolan Coarse Aggregate on the Thermo-Mechanical Properties of Concrete
}

\author{
Abdelilah Bellil ${ }^{1 *}$ (D) , Ayoub Aziz ${ }^{1(D)}$, Mohammed Achab ${ }^{1(D)}$, Abdelmounji Amine ${ }^{2}$ Hamid El Azhari $^{3}$ \\ 1 Geomaterials and Geo-Environment Team (GeoM\&E), GEOBIO Laboratory, GEOPAC Center, Scientific Institute, \\ Mohammed V University in Rabat, Morocco; bellil.abdelilah@gmail.com (A.B.); ayoubaziz100@gmail.com (A.A.); \\ med.achab70@gmail.com (M.A.); \\ 2 Laboratoire de Géosciences Appliquées à l'Ingénierie de l'Aménagement, Faculty of Sciences, Hassan II University, \\ Casablanca, Morocco; Ab.amine@live.fr (A.A.); \\ 3 Hassan First University of Settat, Faculty of Sciences and Technology, Laboratory Physico-chemistry of Processes and \\ Materials (PCPM), Research Team: Geology of Mining and Energy Resources (GRME), 26002, Settat, Morocco; \\ hamid.elazhari@uhp.ac.ma (H.E.A.); \\ * Correspondence: bellil.abdelilah@gmail.com (A.B.);
}

Scopus Author ID 57202074321

Received: 9.07.2021; Revised: 15.09.2021; Accepted: 18.09.2021; Published: 18.10.2021

Abstract: The present study investigated the effects of the variety and content of three natural pozzolan coarse aggregates on concrete. Natural pozzolan aggregates have been obtained from three volcanoes (Boutagrouine, Timahdite, and Jbel Hebri) located in the Middle Atlas region in Morocco. The three pozzolans studied were characterized, and then a comparison was made by replacing the natural aggregate with the pozzolan aggregate in the concrete in different percentages, namely 25,50 , and 100 $\%$ in volume. The results showed that the variety and content of pozzolan aggregate have a significant impact on the properties of concrete, primarily caused by the characterization of pozzolan aggregate. The density of concrete decreases with the addition of pozzolan aggregate, which decreases depending on the type of pozzolan aggregate used. The highest compressive strength was measured in the concrete specimens prepared with aggregate BP while the lowest compressive strength was noted in the concrete specimens prepared with aggregate RP. On the other hand, the substitution of NA at $100 \%$ by BP, GP, and RP aggregates leads to a decrease in the thermal conductivity of about $67 \%, 62 \%$, and $55 \%$ respectively

Keywords: three varieties of pozzolan; lightweight concrete; mechanical strength; thermal conductivity.

(C) 2021 by the authors. This article is an open-access article distributed under the terms and conditions of the Creative Commons Attribution (CC BY) license (https://creativecommons.org/licenses/by/4.0/).

\section{Introduction}

In the recent construction industry, concrete is the most widely used material in all construction areas due to its usefulness and relatively low cost. In the last decade, many studies have focused on improving certain characteristics of concrete, such as lightness and thermal and sound insulation [1-4]. In this regard, the use of lightweight aggregates (LWAC) in concrete replacing normal aggregates is one of the ways to reduce the weight of a structure and improve its thermal and sound insulation due to the air voids in lightweight aggregates (LWA) [5-10].

Based on a literature review, natural pozzolanic aggregate is chosen as a replacement material for coarse aggregate. Pozzolans are pyroclastic volcanic rocks formed by the 
fragmentation of magma (pyroclastics) projected into the air following the bursting of ascending gas bubbles during strombolian and basic eruptions [11]. The rapid decrease in pressure and temperature leads to the formation of a microporous and amorphous structure due to the release of gas dissolved in the magma particles and the process of its quenching, while a non-explosive eruption expelled to the surface as a flow causes the crystallization of the magma due to its slow cooling rate [12].

There are many studies on natural pozzolan and its application in different fields [1317]. In this sense, the use of pozzolan in cement materials offers advantages on several physicochemical properties such as improved workability, reduced heat of hydration, low permeability, mechanical strength, setting times, volume expansion, durability, impermeability, resistance to thermal cracking, and resistance to sulfide attack [18-20]. Moreover, due to its chemical composition and vitreous nature, finely ground natural pozzolan is highly regarded as precursors for geopolymer synthesis. Their reactions with an activating solution provide environmentally friendly materials with interesting materials physicochemical and mechanical properties [21-26]. In this regard, several authors have used natural pozzolan to manufacture ceramic supports for microfiltration membranes to replace the renowned industrial supports such as alumina, which are extremely limited due to their high cost [2729]. Pozzolan also finds applications in construction. Their introduction in the form of aggregates reduces the weight of concrete and decreases the thermal conductivity of concrete to improve the energy efficiency of buildings [30].

This paper reports the results of a study conducted to investigate and compare the effect of three varieties of pozzolan, sampled in the central Middle Atlas region, on concrete's physical, mechanical, and thermal properties.

\section{Materials and Methods}

\subsection{Materials.}

Ordinary Portland cement manufactured by Lafarge, according to the Moroccan standard NM 10.01.004, was used for all mixes. The main characteristics of this cement are SO3 content less than $4 \%$, average compressive strength at 28 days equal to $40 \mathrm{MPa}$, and specific gravity is $3.15 \mathrm{~g} / \mathrm{cm}^{2}$. River sand with a maximum size of $2 \mathrm{~mm}$ was used as fine aggregate (FA). The density and absorption of the sand used was (2.64 and 3.84\%, respectively). The natural coarse aggregate used (NCA) is crushed gravel with a nominal maximum size of $12 \mathrm{~mm}$. The natural pozzolan used in this study was obtained from three volcanoes (Boutagrouine, Timahdite, and Jbel Hebri) located in the Middle Atlas region. Three varieties of natural pozzolans were used; black pozzolan (BP) from Boutagrouine, grey pozzolan (GP) from Timahdite and red pozzolan (RP) from Jbel Hebri. The pozzolans used in this work were washed with distilled water to remove the clayey part, dried at a temperature of $105^{\circ} \mathrm{C}$, and then crushed and sieved to a nominal maximum size of $12 \mathrm{~mm}$. The physical properties of the three varieties of natural pozzolan and the coarse aggregates are shown in Table 1.

Table 1. The physical properties of coarse aggregates.

\begin{tabular}{|c|c|c|c|c|}
\hline & NCA & BP & GP & $\mathbf{R P}$ \\
\hline Density (D) $\left(\mathrm{g} / \mathrm{cm}^{3}\right)$ & & 0.95 & 1.09 & 1.13 \\
\hline Porosity (P) (\%) & -- & 32.6 & 27.8 & 15.1 \\
\hline Water absorption (A) (\%) & 1.60 & 31.2 & 22.33 & 19.7 \\
\hline Abrasion loss (\%) & 24.2 & 42,6 & 56,2 & 69,9 \\
\hline
\end{tabular}




\subsection{Experimental procedures.}

To obtain comparable results, ten concrete mixes were prepared by varying the rate of substitution by weight of natural aggregates by natural pozzolan aggregates. The natural aggregates were replaced by $25 \%, 50 \%$, and $100 \%$ in volume by the different varieties of natural pozzolan (NP). Before their inclusion in the mixes, the pozzolan aggregates were immersed in water for 12 hours and then dried in the open air until saturation conditions were reached on the dry surface.

To ensure comparability, the mixtures were produced with the same target slump of $125 \pm 10 \mathrm{~mm}$. In all mixtures, the effective water/cement ratio (w/c) was kept constant (0.6). The proportions of the concrete mix are shown in Table 2.

Table 2. Mix proportions for all series of concrete mixes $(\mathrm{kg} / \mathrm{m} 3)$.

\begin{tabular}{|c|c|c|c|c|c|c|}
\hline Mix & OPC & NFA & NCA & BP & GP & $\mathbf{R P}$ \\
\hline $\mathbf{R C}$ & 350 & 680 & 1176 & -- & -- & -- \\
\hline Pz_B ${ }_{25}$ & 350 & 680 & 882 & 151 & -- & -- \\
\hline Pz_B50 & 350 & 680 & 588 & 302 & -- & -- \\
\hline $\mathbf{P z}_{-} \mathbf{B}_{100}$ & 350 & 680 & 0 & 603 & -- & -- \\
\hline Pz_R 25 & 350 & 680 & 882 & -- & 162 & -- \\
\hline Pz_R50 & 350 & 680 & 588 & -- & 334 & -- \\
\hline Pz_R $R_{100}$ & 350 & 680 & 0 & -- & 667 & -- \\
\hline Pz_G25 & 350 & 680 & 882 & -- & -- & 176 \\
\hline Pz_G50 & 350 & 680 & 588 & -- & -- & 353 \\
\hline $\mathbf{P z}_{-} \mathbf{G}_{100}$ & 350 & 680 & - & -- & - & 705 \\
\hline
\end{tabular}

\subsection{Characterization methods.}

The bulk density of the manufactured concretes at 28 days of age was calculated as the mass divided by the cube $(100 \mathrm{~mm})$ bulk volume, according to ASTM C642-13. The compressive strength of the manufactured concretes was measured in cubic samples $(10 \mathrm{~cm})$ after 7, 14, and 28 days. The flexural strength was measured on prismatic samples (40x40x160 $\mathrm{mm} 3$ ) after 7, 14, and 28 days. Three specimens were tested for tests (density, compressive strength, and flexural strength), and the results represent the average of three tested specimens.

The thermal properties of the elaborated concrete were measured on samples $(8 x 8 x 4$ $\mathrm{cm}^{3}$ ) after 28 days of hardening using a CT-meter device that operates on the principle of the hot wire according to NF EN ISO 8894-1. The temperature range of the measurement test is from 20 to $30{ }^{\circ} \mathrm{C}$ for thermal conductivity materials from 0.01 to $10 \mathrm{~W} \mathrm{~m}^{-1} \mathrm{~K}^{-1}$, while the measurement accuracy was $5 \%$.

SEM/EDX analysis: The different types of pozzolan used were analyzed with a scanning electron microscope (x 2500), coupled with beam energy dispersive spectrometry (SEM-EDS) of the JEOL JSMTT 100 type, after their surface metallization (deposition of a gold ultra-thin layer of using a JEOL JFC-2300 HR secondary vacuum metallizer).

\section{Results and Discussion}

\subsection{Pozzolan aggregates characterization.}

\subsubsection{Geological and volcanological overview.}

Basaltic volcanism is the most common type of volcanic activity on the planet $[31,32]$. The Middle-Atlas was the scene of paroxysmal volcanic activity during the Plio-Quaternary time, making it the youngest and widest volcanic field in Morocco [33,34]. This volcanic 
activity was concentrated in the Middle-Atlas tabular part, particularly on the Azrou-Timahdite plateau, where almost 80 volcanic edifices have been identified [47]. Two-thirds of these volcanic edifices are cones induced by Strombolian activity, whereas one-third are maars induced by hydromagmatic activity. Strombolian dynamics consist of a dry volcanic activity characterized by a series of massive gas bubble bursts near the magma conduit's surface, propelling slag and bombs of various sizes $[35,36]$. The organization and accumulation of products within strombolian cones are concentrated around the emission center $[37,38]$. The heavier ballistic pyroclasts fall near the center (core cone facies). Their reddish tone results from aerial oxidation caused by a high-temperature depositional process (e.g., Jbel Hebri red pozzolan). The lightest elements fall along the periphery (rim cone facies) [39]. Their dark tone indicates that they have cooled and stabilized to be stainless during their ballistic trajectory before landing (e.g. Timahdite Pozzolan) [38]. Phreatomagmatic dynamic style is derived from a highly explosive eruption driven by the explosive contact between ascending magma and shallow or surface water $[40,41]$. This phreatomagmatic dynamism leads to the formation of wide craters in the bedrock, bordered by a tuff ring of ash, lapilli, bombs, and fragments of the substrate of black hue (e.g., pozzolan of Boutagerouine) (Figure 1).

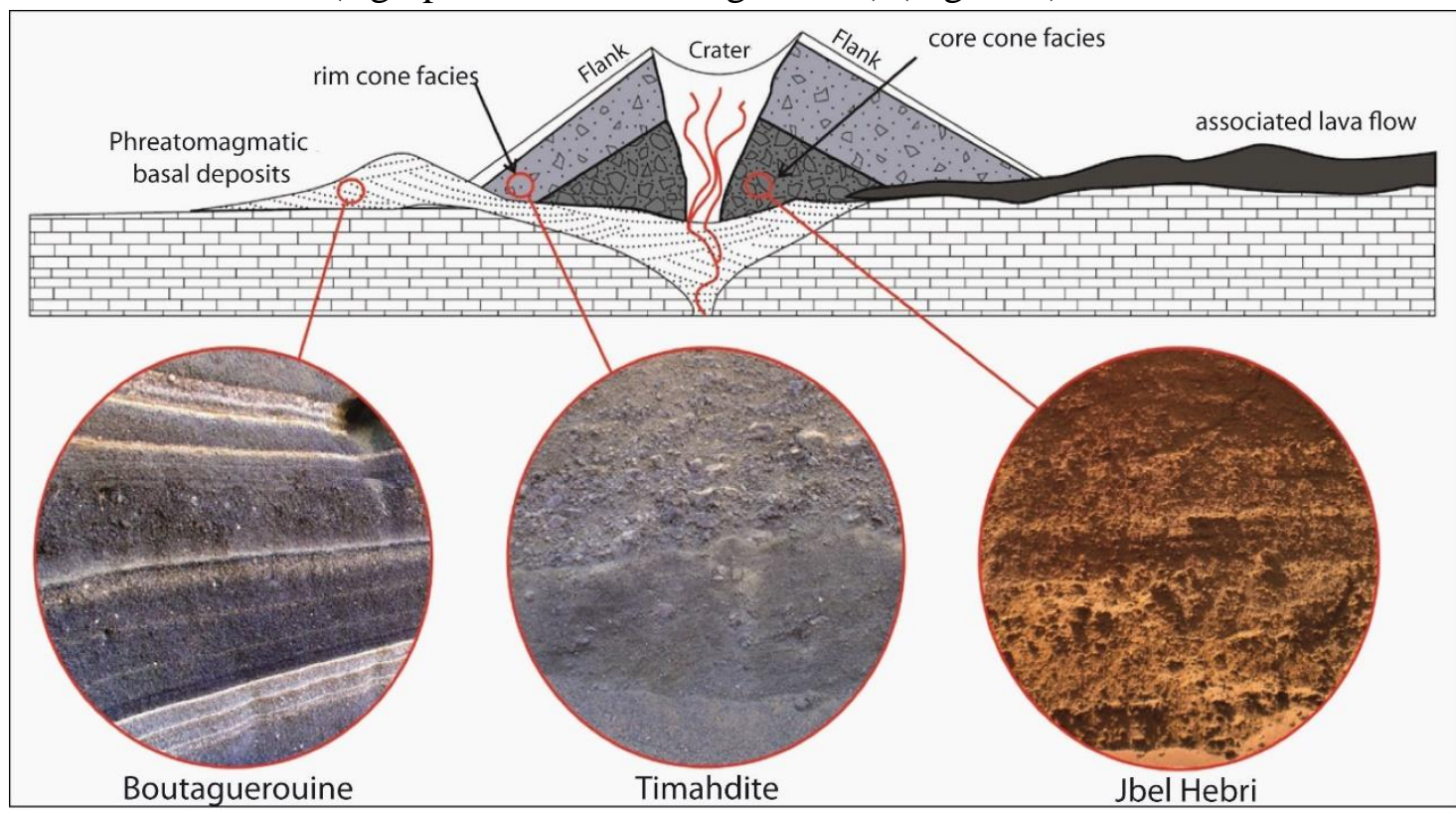

Figure 1. Location of sampling from different zones of the volcano structure.

3.1.2. Physical characterization (density, porosity, and water absorption).

The technological tests conducted on the three types of pozzolan used in this study show that the red pozzolan of Jbel Hebri has the highest density, about $1.13 \mathrm{~g} / \mathrm{cm}^{3}$, followed by the pozzolan of Timahdite and Boutagerouine 1.09 and $0.95 \mathrm{~g} / \mathrm{cm}^{3}$, respectively. In addition, the sample of Boutagerouine has the highest porosity and water absorption, while the sample Jbel Hebri shows the lowest porosity and water absorption. In this context, it can be said that as the pozzolan fragments move away from the emission center, their hardness and porosity increase.

\subsubsection{Morphological characterization.}

The observation of pozzolan fragments under the scanning electron microscope (Figure 2) shows the different pozzolan porous textures. In detail, the pozzolan Boutagerouine has a very porous structure consisting mainly of open pores of micrometer to millimeter size, which 
justifies its low bulk density and high porosity (Table 1). The Jbel Hbri pozzolan has a less porous structure dominated by closed pores of micrometer to millimeter size, making this pozzolan the densest relatively. As for the Timahdite, pozzolan has a moderately porous texture formed by open and closed pores, which places this pozzolan in terms of physical characteristics between the Jbel Hebri and Boutagerouine pozzolans.
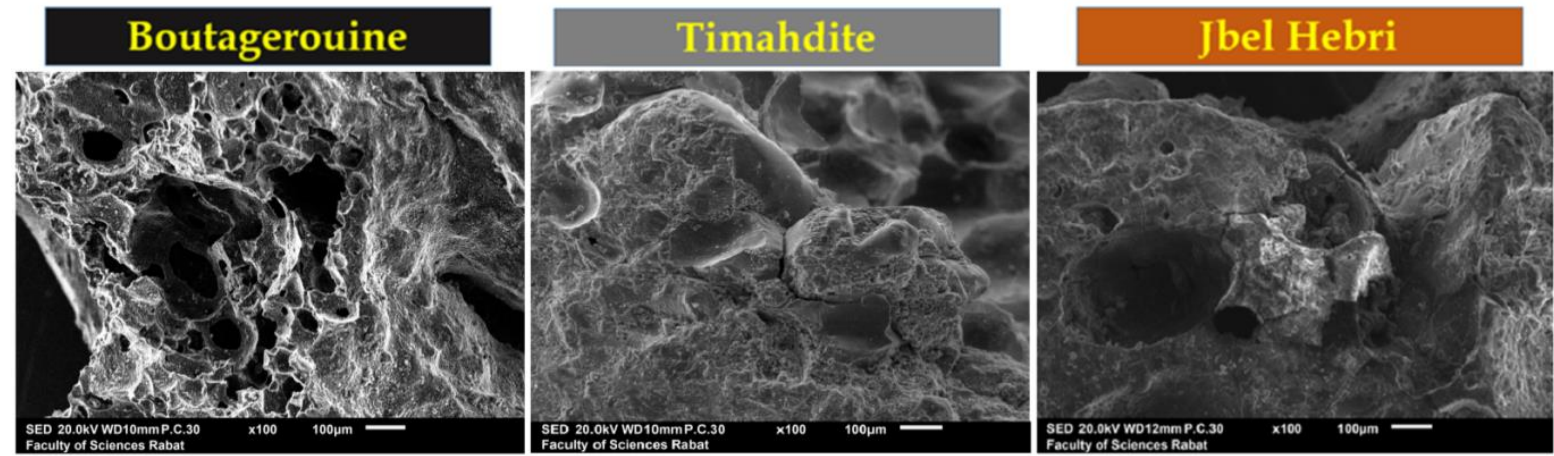

Figure 2. Macroscopic aspect of the pozzolan used in this study.

\subsection{Characterization of elaborate concretes.}

\subsubsection{Density.}

The density of concrete made with different replacement levels of aggregates pozzolan at age 28 days curing is given in Table 3.

Table 3 clearly shows that the hardened concrete density values become lower for three types of PA as the substitution percentage of NCA with PA increases. For example, the substitution of $100 \%$ of BP, GP and RP aggregates decreases the density by $27 \%, 23.4 \%$, and $19.8 \%$, respectively. The reduction in dry density of concrete after incorporating natural pozzolan aggregates other types of lightweight aggregates is also observed in other studies[17,42,43].

Comparing the effects of all three studied pozzolan aggregates on density, a lower density was measured in the concrete specimens prepared with the BP aggregates, while the highest density was noted in the concrete specimens prepared with RP aggregates, and this can be explained by the high porosity of the BP aggregates (Table 1). From 50\% of replacement, the dry density of concrete was less than $2000 \mathrm{~kg} / \mathrm{m}^{3}$ (Table 3), which is the upper limit established in EN 206-1 (2005) for lightweight concrete.

Table 3. Dry density of concrete.

\begin{tabular}{|c|c|c|c|c|c|c|c|c|c|c|}
\hline Mixes & $\mathbf{R C}$ & $\mathbf{P z}_{-} \mathbf{B}_{25}$ & $\mathbf{P z}_{-} \mathbf{B}_{50}$ & Pz_B $\mathbf{B}_{100}$ & $\mathbf{P z}_{-} \mathbf{G}_{25}$ & Pz_G50 & Pz_G $\mathbf{G}_{100}$ & $\mathbf{P z}_{-} \mathbf{R}_{25}$ & $\mathbf{P z} \_\mathbf{R}_{50}$ & Pz_R $\mathbf{R}_{100}$ \\
\hline Density $\left(\mathrm{kg} / \mathrm{m}^{3}\right)$ & 2225 & 2055 & 1845 & 1624 & 2095 & 1855 & 1705 & 2121 & 1902 & 1785 \\
\hline
\end{tabular}

\subsubsection{Mechanical properties.}

The compressive and flexural strength of different varieties of pozzolan aggregate concrete with different replacement percentages were tested, and each result was the average of measurements for three specimens, as shown in Figures 3 and 4.

As expected, the compressive decrease with an increase in NCA replacement by all types of pozzolan aggregate at all ages (Figure 3). An increase of different pozzolan aggregate replacement up to $100 \%$ resulted in the decrease of the compression strengths at age $28 \mathrm{~d}$ by (30\% of BP100), (35.3\% of GP100), and (40\% of GP100) as compared to the control concrete. 
This reduction was mainly due to the porosity of all types of pozzolan aggregates compared of NCA.

A comparison of the strengths in Figure 4 (a) indicates that the highest compressive strength was measured in the concrete specimens prepared with the BP aggregate. In contrast, the lowest compressive strength was noted in the concrete specimens prepared with RP aggregate. For RP, the compressive strength at $28 \mathrm{~d}$, varies from 44.7 to $32.86 \mathrm{MPa}$, for GP, from 41.5 to $3.4 \mathrm{MPa}$, and this ratio ranges for RP from 28 to $39.8 \mathrm{MPa}$. Moreover, the replacement percentage increases, the compressive strength values of all specimens decrease, and the corresponding trends are the same. When the replacement percentage is the same, the compressive strength value of PB is obviously larger than that of GP and RP.

In Table 1, the data on loss on abrasion provide evidence of the weak nature of the RP and GP aggregates compared to the BP aggregates. The compressive strength of BP aggregate concrete was more than that of the GP and RP aggregate concrete. According to Aitcin and Mehta [44], the strength of coarse aggregates may control the ultimate strength of concrete. Moreover, the higher absorption into the BP aggregate, eliminates the accumulation of water in the fresh matrix in the vicinity of the aggregate, which makes the intermediate transition zone in the aggregates denser $[45,46]$ and contributes to the increased compressive strength of concrete prepared with these aggregates.

The results of the flexural strength of different varieties of pozzolan aggregate concrete at 28 days are shown in Figure 4 (b). It can be seen that flexural strength decreased with the increase of pozzolan aggregate content. The RP aggregate concrete presented the lowest loss in strength compared to the control concrete. The results for the $100 \%$ substitution of NA with pozzolan aggregate showed losses of 26.4\%, 28.6\%, and 32.8\% for BP100, GP100, and RP100, respectively. Like the compressive strength test, when the replacement percentage is the same, the flexural strength value of BP aggregate concrete is obviously larger than that of GP and RP aggregate concrete. This is a result of the difference in the mechanical and physical properties of the aggregates.
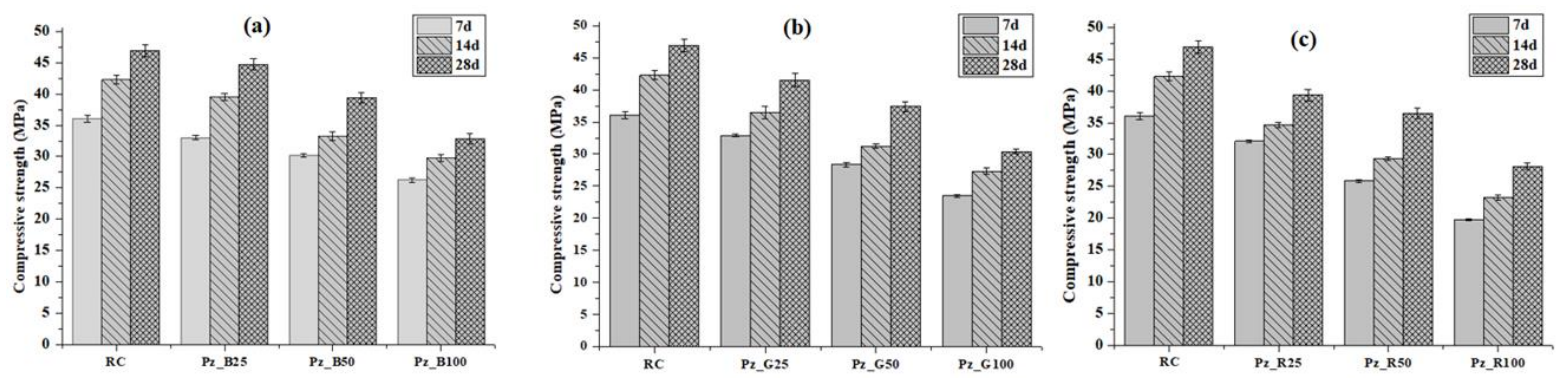

Figure 3. Compressive strength of specimens as a function of age.
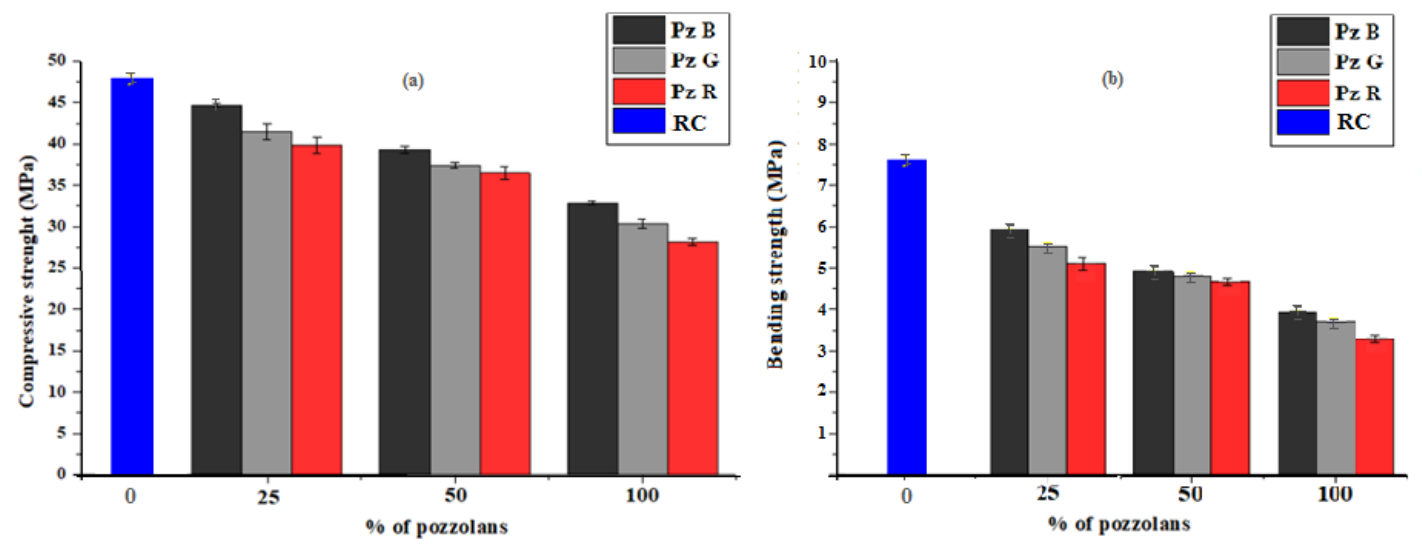

Figure 4. (a) Compressive strength and (b) bending strength of specimens test results at 28 days. 


\subsubsection{Thermal conductivity.}

The thermal conductivity of tested lightweight concretes with the incorporation of different pozzolan aggregates at 28 days is given in Figure 5. The thermal conductivity decreased with the increasing pozzolan aggregate content; a reduction up to $67 \%$ for BP $100 \%$, $62 \%$ for GP100\%, and 55\% for RP100\%, compared to the reference material, was observed. Apparently, the increasing content of pozzolan aggregates led to a decrease in thermal conductivity. The reason for the decrease in thermal conductivity could be attributed to: (i) the porosity of concretes with higher pozzolan aggregates amount (ii) the lower thermal conductivity of pozzolan aggregates in comparison with NCA.

The substitution of NCA by $25 \%, 50 \%$, and $100 \%$ of BP aggregates leads to a decrease in the thermal conductivity of about $29.8 \%, 50.5 \%$, and $67 \%$, respectively. On the other hand, the substitution by GP aggregates decreases TC. The decrease is approximately $28.7 \%, 45 \%$, and $62 \%$ for the replacement rates of $25 \%, 50 \%$, and $100 \%$, respectively, lower than those of BP aggregates substitution. Also, the substitution by RP aggregates contributes to the decrease in thermal conductivity with $19.7 \%, 37.8 \%$, and $55 \%$ for $25 \%, 50 \%$, and $100 \%$, respectively, but remains lower than that of BP or GP aggregates substitutions. This difference in thermal conductivity between the three pozzolan aggregates used is mainly due to the different porosity values of the pozzolan aggregates (Table 1).

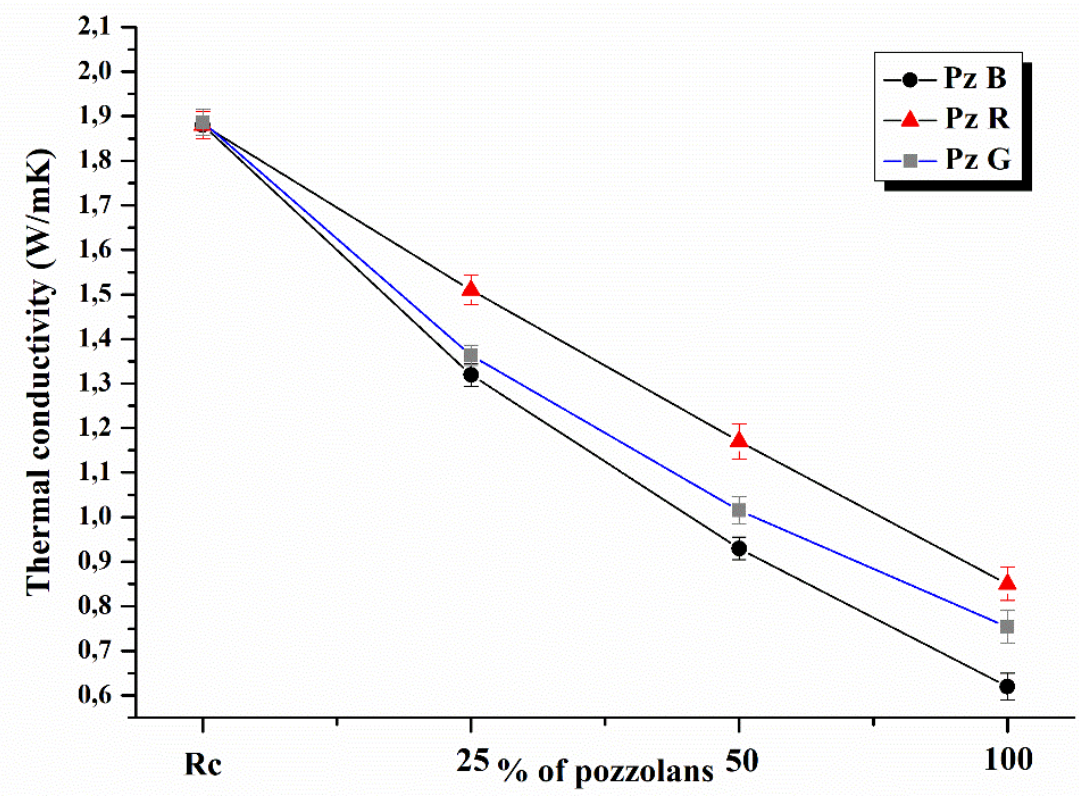

Figure 5. Thermal conductivity test results at 28 days in the dry state.

The correlation between the thermal conductivity and density of all mixes at 28 days is presented in Fig. XX. As seen in Figure 6, a linear relationship is written in the form $\mathrm{y}=0.0019 \mathrm{x}-2.4442$ with $\mathrm{R} 2=0.915$ between the unit weight and thermal conductivity of concrete. Zhou and Books [6] indicate that the thermal conductivity of concrete decreases almost linearly with the decrease of material density. This implies that the thermal conductivity increases with the increase of density. From this, it can be concluded that the pozzolan aggregates reduce the density of concrete and thus improve its thermal conductivity. 




Figure 6. Relationship between dry density and thermal conductivity of samples at 28 days.

\section{Conclusions}

The physical properties of the three pozzolans used in this study show that the further the pozzolan fragments move away from the emission center during the eruption, the more their hardness and porosity increase.

Dry density is lower in all pozzolan than in conventional concrete, and its density declines with rising natural pozzolan aggregate content. The lowest density was obtained by replacing the natural aggregate with the black pozzolan aggregate.

In all the natural pozzolan-based concretes, the 28-day compressive strength is lower than that of conventional concrete. Comparing between pozzolan aggregates studied in the same replacement content, it is observed that black pozzolan aggregate can be given the highest strength. Strength loss is greater in mixes bearing read pozzolan aggregate.

The control concrete has a high thermal conductivity compared to the other concretes with all types of pozzolan aggregate, implying that the NP decreased the thermal conductivity. The lowest thermal conductivity was observed with the black pozzolan aggregate.

\section{Funding}

This research received no external funding.

\section{Acknowledgments}

This work takes part in the V2GV project framework (Evaluating of Volcanic Geo-Materials and Geo-Sites in Morocco), supported by the Hassan II Academy of Sciences and Techniques (AH2ST) which we thank. We would also like to thank Prof. Iz-Eddine El Amrani El Hassani, Prof. Abdelali El Khadiri, and Prof. Hamid Slimani for their indispensable collaboration in this research.

\section{Conflicts of Interest}

The authors declare no conflict of interest. 


\section{References}

1. Barbieri, V.; Lassinantti Gualtieri, M.; Manfredini, T.; Siligardi, C. Lightweight Concretes Based on Wheat Husk and Hemp Hurd as Bio-Aggregates and Modified Magnesium Oxysulfate Binder: Microstructure and Technological Performances. Constr. Build. Mater. 2021, 284, 122751, https://doi.org/10.1016/j.conbuildmat.2021.122751.

2. Cavalline, T.L.; Gallegos, J.; Castrodale, R.W.; Freeman, C.; Liner, J.; Wall, J. Influence of Lightweight Aggregate Concrete Materials on Building Energy Performance. Buildings 2021, 11, 94, https://doi.org/10.3390/buildings11030094.

3. Chin, C.O.; Yang, X.; Kong, S.Y.; Paul, S.C.; Wong, L.S. Mechanical and Thermal Properties of Lightweight Concrete Incorporated with Activated Carbon as Coarse Aggregate. J. Build. Eng. 2020, 31, 101347, https://doi.org/10.1016/j.jobe.2020.101347.

4. Boucedra, A.; Bederina, M.; Ghernouti, Y. Study of the Acoustical and Thermo-Mechanical Properties of Dune and River Sand Concretes Containing Recycled Plastic Aggregates. Constr. Build. Mater. 2020, 256, 119447, https://doi.org/10.1016/j.conbuildmat.2020.119447.

5. Ahmad, M.R.; Chen, B.; Farasat Ali Shah, S. Investigate the Influence of Expanded Clay Aggregate and Silica Fume on the Properties of Lightweight Concrete. Constr. Build. Mater. 2019, 220, 253-266, https://doi.org/10.1016/j.conbuildmat.2019.05.171.

6. Zhou, H.; Brooks, A.L. Thermal and Mechanical Properties of Structural Lightweight Concrete Containing Lightweight Aggregates and Fly-Ash Cenospheres. Constr. Build. Mater. 2019, 198, 512-526, https://doi.org/10.1016/j.conbuildmat.2018.11.074.

7. Salmasi, F.; Mostofinejad, D. Investigating the Effects of Bacterial Activity on Compressive Strength and Durability of Natural Lightweight Aggregate Concrete Reinforced with Steel Fibers. Constr. Build. Mater. 2020, 251, 119032, https://doi.org/10.1016/j.conbuildmat.2020.119032.

8. Sahoo, S.; Selvaraju, A.K.; Prakash, S.S. Mechanical Characterization of Structural Lightweight Aggregate Concrete Made with Sintered Fly Ash Aggregates and Synthetic Fibres. Cem. Concr. Compos. 2020, 113, 103712, https://doi.org/10.1016/j.cemconcomp.2020.103712.

9. Alaskar, A.; Alshannag, M.; Higazey, M. Mechanical Properties and Durability of High-Performance Concrete Internally Cured Using Lightweight Aggregates. Constr. Build. Mater. 2021, 288, 122998, https://doi.org/10.1016/j.conbuildmat.2021.122998.

10. Khan, M.S.; Khattak, A.; Yaqoob, M.; Alam, K. Strength And Thermal Conduction Assessment Of Lightweight Aromatic Hydrocarbon Waste Polystyrol Glass Concrete. J. Eng. Sci. Technol. 2021, 16, 10821097, https://jestec.taylors.edu.my/Vol\%2016\%20issue\%202\%20April\%202021/16_2_14.pdf.

11. Minières (France), B. de recherches géologiques et; Rocher, P. Mémento Roches et Minéraux Industriels: Ponces et Pouzzolanes; BRGM 1995, http://infoterre.brgm.fr/rapports/RR-38759-FR.pdf.

12. Firdous, R.; Stephan, D.; Djobo, J.N.Y. Natural Pozzolan Based Geopolymers: A Review on Mechanical, Microstructural and Durability Characteristics. Constr. Build. Mater. 2018, 190, 1251-1263, https://doi.org/10.1016/j.conbuildmat.2018.09.191.

13. Aziz, A.; El Amrani El Hassani, I.-E.; El Khadiri, A.; Sadik, C.; El Bouari, A.; Ballil, A.; El Haddar, A. Effect of Slaked Lime on the Geopolymers Synthesis of Natural Pozzolan from Moroccan Middle Atlas. J. Aust. Ceram. Soc. 2020, 56, 67-78, https://doi.org/10.1007/s41779-019-00361-3.

14. Bahmyari, H.; Ajdari, M.; Vakili, A.; Ahmadi, M.H. The Role of the Cement, Lime, and Natural Pozzolan Stabilizations on the Mechanical Response of a Collapsible Soil. Transp. Infrastruct. Geotechnol. 2021, 8, 452-472, https://doi.org/10.1007/s40515-020-00146-3.

15. Sanjuán, M.Á.; Suárez-Navarro, J.A.; Argiz, C.; Mora, P. Assessment of Natural Radioactivity and Radiation Hazards Owing to Coal Fly Ash and Natural Pozzolan Portland Cements. J. Radioanal. Nucl. Chem. 2020, 325, 381-390, https://doi.org/10.1007/s10967-020-07263-w.

16. Omrane, M.; Rabehi, M. Effect of Natural Pozzolan and Recycled Concrete Aggregates on Thermal and Physico-Mechanical Characteristics of Self-Compacting Concrete. Constr. Build. Mater. 2020, 247, 118576, https://doi.org/10.1016/j.conbuildmat.2020.118576.

17. Bellil, A.; Aziz, A.; El Hassani, I.-I.E.A.; Achab, M.; El Haddar, A.; Benzaouak, A. Producing of Lightweight Concrete from Two Varieties of Natural Pozzolan from the Middle Atlas (Morocco): Economic, Ecological, and Social Implications. Silicon 2021, 1-12, https://doi.org/10.1007/s12633-021-01155-8.

18. Ramachandran, V.S. Concrete Admixtures Handbook: Properties, Science and Technology; William Andrew, 1996.

19. Uzal, B.; Turanli, L. Studies on Blended Cements Containing a High Volume of Natural Pozzolans. Cem. Concr. Res. 2003, 33, 1777-1781, https://doi.org/10.1016/S0008-8846(03)00173-X.

20. Rodriguez-Camacho, R.E.; Uribe-Afif, R. Importance of Using the Natural Pozzolans on Concrete Durability. Cem. Concr. Res. 2002, 32, 1851-1858, https://doi.org/10.1016/S0008-8846(01)00714-1.

21. Moon, J.; Bae, S.; Celik, K.; Yoon, S.; Kim, K.-H.; Kim, K.S.; Monteiro, P.J. Characterization of Natural Pozzolan-Based Geopolymeric Binders. Cem. Concr. Compos. 2014, 53, 97-104, https://doi.org/10.1016/j.cemconcomp.2014.06.010. 
22. Bondar, D.; Lynsdale, C.J.; Milestone, N.B.; Hassani, N.; Ramezanianpour, A.A. Effect of Heat Treatment on Reactivity-Strength of Alkali-Activated Natural Pozzolans. Constr. Build. Mater. 2011, 25, 4065-4071, https://doi.org/10.1016/j.conbuildmat.2011.04.044.

23. Vafaei, M.; Allahverdi, A. Influence of Calcium Aluminate Cement on Geopolymerization of Natural Pozzolan. Constr. Build. Mater. 2016, 114, 290-296, https://doi.org/10.1016/j.conbuildmat.2016.03.204.

24. Robayo-Salazar, R.A.; de Gutiérrez, R.M.; Puertas, F. Effect of Metakaolin on Natural Volcanic PozzolanBased Geopolymer Cement. Appl. Clay Sci. 2016, 132-133, 491-497, https://doi.org/10.1016/j.clay.2016.07.020.

25. Ibrahim, M.; Johari, M.A.M.; Rahman, M.K.; Maslehuddin, M. Effect of Alkaline Activators and Binder Content on the Properties of Natural Pozzolan-Based Alkali Activated Concrete. Constr. Build. Mater. 2017, 147, 648-660, https://doi.org/10.1016/j.conbuildmat.2017.04.163.

26. Kani, E.N.; Allahverdi, A.; Provis, J.L. Efflorescence Control in Geopolymer Binders Based on Natural Pozzolan. Cem. Concr. Compos. 2012, 34, 25-33, https://doi.org/10.1016/j.cemconcomp.2011.07.007.

27. Karim, A.; Achiou, B.; Bouazizi, A.; Aaddane, A.; Ouammou, M.; Bouziane, M.; Bennazha, J.; Younssi, S.A. Development of Reduced Graphene Oxide Membrane on Flat Moroccan Ceramic Pozzolan Support. Application for Soluble Dyes Removal. J. Environ. Chem. Eng. 2018, 6, 1475-1485, https://doi.org/10.1016/j.jece.2018.01.055.

28. Achiou, B.; Elomari, H.; Bouazizi, A.; Karim, A.; Ouammou, M.; Albizane, A.; Bennazha, J.; Younssi, S.A.; El Amrani, I.E. Manufacturing of Tubular Ceramic Microfiltration Membrane Based on Natural Pozzolan for Pretreatment of Seawater Desalination. Desalination 2017, 419, 181187, https://doi.org/10.1016/j.desal.2017.06.014.

29. Achiou, B.; Beqqour, D.; Elomari, H.; Bouazizi, A.; Ouammou, M.; Bouhria, M.; Aaddane, A.; Khiat, K.; Younssi, S.A. Preparation of Inexpensive NaA Zeolite Membrane on Pozzolan Support at Low Temperature for Dehydration of Alcohol Solutions. J. Environ. Chem. Eng. 2018, 6, 44294437, https://doi.org/10.1016/j.jece.2018.06.049.

30. Bouyahayaoui, A.; Cherkaoui, M.; Abidi, L.; Cherradi, T. Mechanical and Chemical Characterisation of Pozzolan of Middele Atlas in Morocco. Int. J. 2018, 14, 126-134, https://doi.org/10.21660/2018.41.91013.

31. Wilson, L.; Head III, J.W. Ascent and Eruption of Basaltic Magma on the Earth and Moon. J. Geophys. Res. Solid Earth 1981, 86, 2971-3001, https://doi.org/10.1029/JB086iB04p02971.

32. Schmincke, H.-U. Volcanoes and climate. Volcanism 2004, 259-272, https://doi.org/10.1007/978-3-64218952-4_14.

33. Martin, J. Le Moyen Atlas Central, Étude Géomorphologique. 1981.

34. Harmand, C.; Cantagrel, J.M. Le Volcanisme Alcalin Tertiaire et Quaternaire Du Moyen Atlas (Maroc): Chronologie K/Ar et Cadre Géodynamique. J. Afr. Earth Sci. 1984, 2, 51-55, https://doi.org/10.1016/08995362(84)90019-8.

35. Vergniolle, S.; Brandeis, G. Strombolian Explosions: 1. A Large Bubble Breaking at the Surface of a Lava Column as a Source of Sound. J. Geophys. Res. Solid Earth 1996, 101, 20433-20447, https://doi.org/10.1029/96JB01178.

36. Houghton, B.F.; Gonnermann, H.M. Basaltic Explosive Volcanism: Constraints from Deposits and Models. Geochemistry 2008, 68, 117-140, https://doi.org/10.1016/j.chemer.2008.04.002.

37. Blackburn, E.A.; Wilson, L.; Sparks, R.J. Mechanisms and Dynamics of Strombolian Activity. J. Geol. Soc. 1976, 132, 429-440, https://doi.org/10.1144/gsjgs.132.4.0429.

38. Taddeucci, J.; Edmonds, M.; Houghton, B.; James, M.R.; Vergniolle, S. Hawaiian and Strombolian eruptions. Hawaiian and Strombolian Eruptions. The encyclopedia of volcanoes (Second Edition) 2015, 485-503, https://doi.org/10.1016/B978-0-12-385938-9.00027-4.

39. Amine, A.; El Hassani, I.-E.E.A.; Remmal, T.; El Kamel, F.; De Vries, B.V.W.; Boivin, P. Geomorphological Classification and Landforms Inventory of the Middle-Atlas Volcanic Province (Morocco): Scientific Value and Educational Potential. Quaest. Geogr. 2019, 38, 107-129, https://doi.org/10.2478/quageo-2019-0010.

40. Wohletz, K.H.; Sheridan, M.F. Hydrovolcanic Explosions; II, Evolution of Basaltic Tuff Rings and Tuff Cones. Am. J. Sci. 1983, 283, 385-413, https://doi.org/10.2475/ajs.283.5.385.

41. Németh, K.; Cronin, S.J. Volcanic Structures and Oral Traditions of Volcanism of Western Samoa (SW Pacific) and Their Implications for Hazard Education. J. Volcanol. Geotherm. Res. 2009, 186, 223237, https://doi.org/10.1016/j.jvolgeores.2009.06.010.

42. Zhu, L.; Dang, F.; Xue, Y.; Ding, W.; Jiao, K. Experimental Investigation of the Thermal and Mechanical Properties of Lightweight Aggregate Concrete Mixed with Microencapsulated Phase Change Materials. Int. J. Energy Res. 2021, 45, 12864-12878, https://doi.org/10.1002/er.6617.

43. Burbano-Garcia, C.; Hurtado, A.; Silva, Y.F.; Delvasto, S.; Araya-Letelier, G. Utilization of Waste Engine Oil for Expanded Clay Aggregate Production and Assessment of Its Influence on Lightweight Concrete Properties. Constr. Build. Mater. 2021, 273, 121677, https://doi.org/10.1016/j.conbuildmat.2020.121677.

44. Aïtcin, P.-C.; Mehta, P.K. Effect of Coarse Aggregate Characteristics on Mechanical Properties of HighStrength Concrete. Mater. J. 1990, 87, 103-107. 
45. Wasserman, R.; Bentur, A. Interfacial Interactions in Lightweight Aggregate Concretes and Their Influence on the Concrete Strength. Cem. Concr. Compos. 1996, 18, 67-76, https://doi.org/10.1016/09589465(96)00002-9.

46. Beshr, H.; Almusallam, A.A.; Maslehuddin, M. Effect of Coarse Aggregate Quality on the Mechanical Properties of High Strength Concrete. Constr. Build. Mater. 2003, 17, 97-103, https://doi.org/10.1016/S0950-0618(02)00097-1.

47. Martin, J. Le Moyen Atlas central: Etude Géomorphologique. Notes et Mém. Serv. Géol. Maroc. 1981, $\mathrm{N}^{\circ} 258$ bis. 